University of Warwick institutional repository: http://go.warwick.ac.uk/wrap This paper is made available online in accordance with publisher policies. Please scroll down to view the document itself. Please refer to the repository record for this item and our policy information available from the repository home page for further information.

To see the final version of this paper please visit the publisher's website. Access to the published version may require a subscription.

Author(s): SCOTT WEICH, LOUISE MORGAN, MICHAEL KING and IRWIN NAZARETH

Article Title: Attitudes to depression and its treatment in primary care Year of publication: 2007

Link to published version: http://dx.doi.org/

10.1017/S0033291707000931

Publisher statement: None 


\title{
Attitudes to depression and its treatment in primary care
}

\author{
SCOTT WEICH ${ }^{1 *}$, LOUISE MORGAN ${ }^{2}$, MICHAEL KING ${ }^{3}$ \\ AND IRWIN NAZARETH ${ }^{4}$ \\ ${ }^{1}$ Health Sciences Research Institute, Warwick Medical School, University of Warwick, Coventry, UK; \\ ${ }^{2}$ Dr Foster Ltd, London, UK ${ }^{3}$ Department of Mental Health Sciences, Royal Free and University College \\ Medical School, London, UK; ${ }^{4}$ Department of Primary Care and Population Sciences, Royal Free and \\ University College Medical School, London, UK
}

\begin{abstract}
Background. Undertreatment of depression in primary care is common. Efforts to address this tend to overlook the role of patient attitudes. Our aim was to validate and describe responses to a questionnaire about attitudes to depression and its treatment in a sample with experience of moderate and severe depressive episodes.
\end{abstract}

Method. Cross-sectional survey of 866 individuals with a confirmed history of an ICD-10 depressive episode in the 12 months preceding interview, recruited from 7271 consecutive general practitioner (GP) attendees in 36 general practices in England and Wales. Attitudes to and beliefs about depression were assessed using a 19-item self-report questionnaire.

Results. Factor analysis resulted in a three-factor solution: factor 1, depression as a disabling, permanent state; factor 2, depression as a medical condition responsive to support; and factor 3, antidepressants are addictive and ineffective. Participants who received and adhered to antidepressant medication and disclosed their depression to family and friends had significantly lower scores on factors 1 and 3 but higher scores on factor 2 .

Conclusions. People with moderate or severe depressive episodes have subtle and divergent views about this condition, its outcome, and appropriate help. Such beliefs should be considered in primary care as they may significantly impact on help seeking and adherence to treatment.

\section{INTRODUCTION}

Depression has a community prevalence of about $10 \%$ (Singleton et al. 2001; Layard, 2006) and is expected to become the second highest cause of disease burden worldwide by 2020 (Murray \& Lopez, 1997). The annual cost of depression in England alone was estimated at $£ 9$ billion in 2000 , of which $90 \%$ was attributed to around 110 million lost working days (Thomas $\&$ Morris, 2003). This figure has been estimated at $£ 17$ billion per annum for the UK as a whole,

\footnotetext{
* Address for correspondence: Professor Scott Weich, Health Sciences Research Institute, Warwick Medical School, University of Warwick, Coventry CV4 7AL, UK.

(Email: s.weich@warwick.ac.uk)
}

equivalent to $1.5 \%$ of the gross domestic product (GDP) (Layard, 2006). The prevalence of depression in developed countries has not fallen in recent decades, despite effective treatments, evidence-based guidelines (NICE, 2004) and public education campaigns (Brugha, 1995; Kendrick, 2000; Department of Health, 2001).

The unmet need for treatment becomes even more alarming when considering only cases of severe disorder (Demyttenaere et al. 2004). Only a minority of those suffering from clinically significant episodes of disorder receive and adhere to treatments in keeping with evidence-based guidelines (Scott, 2006). Population-based surveys in the UK, the USA and Canada found that around one-half of those with a recent or 
current depressive episode of at least moderate severity had sought medical care for this (Bebbington et al. 2000), with up to $62 \%$ reporting medical consultation for this problem at some time in the preceding year (Singleton et al. 2001; Brugha et al. 2004; Wang et al. 2005). Previous studies report that $30-40 \%$ of those in the community who are depressed receive medical treatment (medication or psychological treatments) (Lin \& Parikh, 1999; Singleton et al. 2001). This figure fell to less than $25 \%$ when only treatments of 'minimal' adequacy or better were included in the US National Comorbidity Study replication (NCS-R) (Young et al. 2001). The latter study also found that only $15 \%$ of those with major depressive disorder seen in general medical settings (including primary care) in the past year received treatment meeting these criteria. Recent findings indicate increases in rates of medical help seeking and antidepressant prescribing (from around $5 \%$ to $16 \%$ ) during the $1990 \mathrm{~s}$, but not in the use of psychological therapies. Nor was there any significant reduction in the prevalence of depression over the same period (Brugha et al. 2004). The quadrupling of antidepressant prescribing in this period includes a 12 -fold rise in the rate of prescriptions among those free from psychiatric symptoms at the time of interview.

The reasons for these high levels of undertreatment remain unclear, and are likely to be complex. Undertreatment includes failing to seek help, declining care and dropping out of care (Edlund et al. 2002; Anderson et al. 2006). Many years of attempting to improve physicians' performance, including the development and dissemination of guidelines (Kendrick, 2000; Thompson et al. 2000; NICE, 2004), have produced only modest results. More recently, interest has turned to the effects of patients' attitudes to depression and preferences for treatment (Nutting et al. 2002; Jorm et al. 2004; Kessing et al. 2005; Lin et al. 2005; Pyne et al. 2005). Intriguingly, while two recent trials have shown that the efficacy and cost-effectiveness of treatments for depression are greatly enhanced by individuals' preferences for the treatments offered (Rost et al. 2001; Lin et al. 2005; Pyne et al. 2005), a systematic review of studies with patient preference designs has found no such effect (King et al. 2005). However, this literature is characterized by variability in the nature of attitudes and beliefs studied, and the manner in which these are elicited. Most studies have been concerned primarily with adherence to antidepressant treatment (Kessing et al. 2005), and few have explored attitudes about depression as well as treatment preferences. It has been common to concentrate on receptiveness to treatment in general (Cooper-Patrick et al. 1997; Dwight-Johnson et al. 2000), or to psychological or pharmacological treatments (Kessing et al. 2005) more specifically, usually as dichotomous outcomes (Rost et al. 2001; Pyne et al. 2005).

To understand the determinants of undertreatment of depression in primary care, we recruited a large sample of individuals with a recent history of ICD-10 moderate or severe depressive episodes. The aim of the present paper was to validate and describe the responses to a questionnaire about attitudes to depression and its treatment. We hypothesized that (1) those who viewed depression as treatable would be more likely to have received and adhered to evidence-based treatment for their recent depressive episode; (2) those who were positive about the merits of antidepressant medication were more likely to have received and adhered to evidence-based pharmacotherapy; and (3) individuals who perceived depression as shameful and stigmatizing were the least likely $(a)$ to have disclosed a recent episode to family or friends, or $(b)$ to have received and adhered to evidence-based treatment.

\section{METHOD}

\section{Design and setting}

A cross-sectional survey was undertaken in general practices in England and Wales belonging to the UK General Practice Research Framework (GPRF). The GPRF comprises over 1200 general practices throughout the UK involved in epidemiological, primary care and health services research. Thirty-six general practices took part in this study. These were recruited from all regions on the basis of location, socio-economic deprivation (Jarman score for practice, banded as high, medium or low) and practice size (single-handed, 2-3 principals and $\geqslant 4$ principals). We initially proposed to recruit 50 practices and issued a call for expressions of interest within the GPRF. Approximately 60 
practices replied, from which 52 were invited to take part and 46 sent a research nurse to one of three training days. Of the 36 practices that contributed to data collection, 13 were located in Trent, Eastern and West Midlands regions, nine in the North, Yorkshire and the North West, seven in the South West, six in London and the South East, and one in Wales. Although the South West and West Midlands were overrepresented $(56 \%$ v. $22 \%$ of all GPRF practices), and the South East under-represented ( $14 \%$ v. $28 \%$ of GPRF practices), study practices approximated the distribution of GPRF practices in terms of area type (e.g. $31 \%$ in cities or industrial areas versus $31 \%$ for all GPRF practices). Average list sizes were slightly higher for study practices (9911 v. 7399 for all GPRF practices), while deprivation scores tended to be lower (e.g. average Jarman 91 score $5.7 v .7 .9$ for all GPRF practices).

\section{Participants}

Consecutive attendees aged 18-75 at participating general practices with an appointment to see a doctor, nurse or other professional at the practice about themselves were approached in the waiting room. Exclusion criteria included learning difficulties, cognitive impairment that would prevent completion of the study assessments, and inability to communicate in English.

\section{Measures}

Ascertainment of ICD-10 depressive episodes in the preceding 12 months

Individuals who had experienced an ICD-10 depressive episode (index episode) in the 12 months prior to interview were identified using a two-stage procedure. Research nurses from participating practices were trained to administer the study assessments.

Attendees were asked to complete a brief, 10 -item waiting room screening questionnaire containing items taken from the depression section of the 12-month version of the Composite International Diagnostic Interview (CIDI; WHO, 1997). This brief pencil-and-paper questionnaire, which took no more than 5 minutes to complete, was developed for this study. Terminology was the same as that used in the CIDI, with questions that enquired about 'periods when you have felt sad, empty or depressed in the past 12 months'. Replicating the structure of the CIDI, two stem questions asked respectively whether in the past 12 months the respondent recalled 2 weeks or longer 'when nearly every day you have felt sad, empty, or depressed for most of the day' and 'when you lost interest in most things like work, hobbies and other things you usually enjoyed'. Those who answered 'Yes' to either question were asked to complete a further eight items concerning 'the time (or times) in the past 12 months when you felt sad, empty, or depressed or when you lost interest in most things nearly every day for 2 weeks or longer'. These items (each with Yes/No format) used CIDI depression items covering fatigue, appetite, weight loss, insomnia, concentration, and feelings of worthlessness, inferiority and guilt.

A pilot study compared responses to this questionnaire (in a general practice waiting room) against the 12-month version of the CIDI depression section administered by telephone approximately 1 week later. Although too small for definitive statistical analysis, the results suggested that an optimum balance between sensitivity and specificity was likely to be achieved using a cut-off of $\geqslant 5$ (out of 10), including at least one positive response to the first two (stem) questions. This cut-point was also chosen to maximize the positive predictive value in order to minimize costly 'false positive' second-stage interviews. Those scoring at or above this level were invited by telephone (or letter) to participate in a face-to-face interview with a research nurse.

The occurrence of one or more depressive episodes was established at face-to-face interview with a researcher using the depression section from the 12-month version of the CIDI (WHO, 1997). Severity was rated at the time that most symptoms were present concurrently and diagnosis was established using the research version of ICD-10 (WHO, 1993).

\section{Treatments for depression interview}

Sources and types of help sought, general practitioner (GP) consultations, and receipt of and adherence to medication and psychological treatments were assessed using a structured interview designed for this study. This was administered during the second-stage interview to all individuals found to have experienced an ICD-10 depressive episode in the preceding 12 
months. Questions concerned the identity, dose and duration of adherence to all treatments received in respect of the index episode of depression.

This interview was administered directly after the depression section of the 12-month CIDI. As many individuals with depression do not endorse this term, the latter begins by eliciting core symptoms of depression (low mood, loss of interest and/or fatigue) and then referring to the specific 'problems' endorsed rather using than the word 'depression' when asking about other symptoms. The period about which treatment questions were asked was anchored during the CIDI interview by identifying the month in the preceding year when the respondent had the 'largest number of problems [symptoms] at the same time'. Using CIDI terminology ('problems' such as 'feeling sad, empty or depressed, etc.' rather than 'symptoms' or 'depression'), participants were asked to identify the month and the year when this depressive episode began and ended.

Participants were reminded about the "problems' they had described in the preceding year in response to the CIDI questions and the month when these were at their worst. They were then asked if they had spoken with their GP about these problems, and about the timing of the first consultation in respect of this episode.

All possible treatments were first enumerated, starting with medication. Participants were asked if their GP or any other doctor had prescribed any medicines since the time when they had first consulted their doctor about the index episode of depression identified during the CIDI interview. Using a show card containing the names of all antidepressants listed in the British National Formulary (BNF), participants were asked to identify up to three drugs that they had been prescribed. For each drug mentioned, questions covered dose, duration of adherence, and how often, on average, they had remembered to take this medicine. Further questions asked if they were still taking this drug, and if not, why not and whether discontinuation had been discussed with a doctor.

Participants were asked about psychological and other treatments. They were reminded of the month when they reported that the index episode had begun, and were asked if they had been referred to (whether by someone else or by self-referral) a counsellor within the practice, a counsellor outside of the practice, psychiatrist, psychologist, psychotherapist or psychoanalyst, or other mental health professional. Taking each in turn (where endorsed), participants were asked how many sessions they had attended, whether they were still attending and the reasons (where appropriate) for termination.

Finally, this interview asked about disclosure of depression. Participants were asked 'Since [month when the index episode began], have you told any of your family or friends that you [were feeling sad, empty or depressed/had lost interest in most things/lacked energy]?'

\section{Criteria for evidence-based treatments}

Treatments were divided into pharmacological and psychological, and criteria for appropriateness were derived from current evidence-based guidelines. We followed previous studies in operationalizing dose, duration and adherence, and setting thresholds that were consistent with minimally adequate treatment (Wang et al. 2005). Pharmacological treatment was said to have met evidence-based standards when a participant reported having taken (i) a therapeutic dose of an antidepressant, (ii) for at least 4 weeks, (iii) at a minimum frequency of $\geqslant 4$ days per week on average. Therapeutic doses of antidepressant were based on the BNF. This was taken as $\geqslant 75 \mathrm{mg} /$ day of dothiepin or amitryptiline, $\geqslant 20 \mathrm{mg} /$ day of fluoxetine or paroxetine, $\geqslant 75 \mathrm{mg} /$ day of venlafaxine and $>50 \mathrm{mg} /$ day of sertraline. Psychological treatment was considered to have met evidencebased standards when a participant reported referral to a counsellor, psychologist or psychotherapist, and either (i) they attended $\geqslant 3$ sessions, or (ii) the treatment had been completed, or (iii) they were still attending.

\section{Attitudes to depression and its treatment (ADepT questionnaire)}

Participants completed a new 19-item selfreport questionnaire concerning attitudes to depression (13 items) and its treatment (six items). Several items were based on those found in existing measures at the time that our study began (Botega et al. 1992; Priest et al. 1996). Items were selected to address common misconceptions about depression ('You must be careful not to upset someone who has been 
depressed, or they will get ill again'), and the sense of stigma and shame that often accompany this condition ('If other people knew I had been depressed, they would think less of me') as well as views about treatment ('Counselling is an effective way of treating depression'). All items were rated using a five-point scale with responses ranging from 'strongly agree' (5) to 'strongly disagree' (1). Positive and negative phrasing was used to prevent response set bias, and we included two items that asked about possible advantages of depression (e.g. 'People with depression are more creative and imaginative than others'). Questionnaire items are shown in Table 2.

Socio-economic status. This was assessed using questions about employment status, housing tenure, car access, education and financial strain. The latter was assessed using a question commonly used in social surveys, the response to which is highly predictive of current and future rates of psychiatric morbidity (Weich \& Lewis, 1998).

\section{Analysis}

Cronbach's $\alpha$ was calculated to assess the internal reliability of the ADepT questionnaire. We used principal factor analysis to investigate and describe the underlying factor structure of the questionnaire. The number of factors was determined by examination of a scree plot and the size of the eigenvalues (Cattell, 1966). After factor extraction, an orthogonal (varimax) rotation was made to achieve a simpler factor structure. When analysing factor loadings, we chose 0.4 as a cut-off for size of loading to be interpreted. The greater the factor loading, the more the item is a pure measure of the factor. Principal factor analysis was repeated after stratifying by severity of depressive episode, to see whether this affected underlying item response patterns.

Regression-based factor scores were derived from the rotated components, and were normalized to have a mean of 0 and standard deviation of 1 . All analyses were undertaken using Stata 8 (StataCorp, 2004). To reflect the clustered nature of the sample, analyses were undertaken using survey commands that adjust standard errors and $\chi^{2}$ statistics for clustering (autocorrelation) within clinics. Differences in mean factor scores between those who did and did not receive evidence-based treatments, and those who did and did not disclose their depression to family or friends, were estimated using linear (least squares) regression.

\section{RESULTS}

Excluding those who were ineligible, 7718 individuals were asked to take part in screening and $7271(94.2 \%)$ completed the waiting room questionnaire. Of those who completed the questionnaire, $2211(30.4 \%)$ scored above the inclusion threshold for interview. A total of 975 individuals $(44 \cdot 1 \%$ of those with positive screen results) took part in the second stage interview. No statistically significant difference was found in screening score between those who took part in the interview and those who declined or were not available [mean difference $-0.04,95 \%$ confidence interval (CI) -0.18 to $0 \cdot 11, p=0 \cdot 61]$.

At interview, 866 individuals $(88.8 \%$ of those interviewed) were found to have experienced an ICD-10 depressive episode in the preceding 12 months, of whom $812(94 \cdot 2 \%)$ endorsed all three 'core' depressive symptoms. Twelve individuals $(1.4 \%)$ had experienced a mild depressive episode, $175(20 \cdot 3 \%)$ a moderate episode, and $679(78.4 \%)$ a severe depressive episode. Of those with a confirmed depressive episode, 786 (90.8 \%) completed the ADepT questionnaire in full, and analyses were based on this group. The characteristics of the study sample are shown in Table 1 .

In total, 330 individuals with ICD-10 depressive episodes $(38 \cdot 1 \%$ of the sample) reported receipt of and adherence to evidence-based treatment. Two hundred and sixty-seven $(30 \cdot 8 \%$ of the sample) met minimum criteria for evidence-based antidepressant treatment. Only 99 individuals $(11.5 \%$ of the sample) met minimum criteria for evidence-based psychological treatment.

Cronbach's $\alpha$ was 0.73 for the full scale. Principal factor analysis resulted in nine factors with eigenvalues greater than 0 . Inspection of the scree plot (Fig. 1) was consistent with a three-factor solution, although three-, four- and five-factor models were all considered before the former was judged the most parsimonious. Interpretation was not made any clearer, even 
Table 1. Characteristics of the study participants with an ICD-10 depressive episode in the 12 months prior to interview $\left(n=865^{\mathrm{a}}\right)$, comparing mild and moderate versus severe depressive episodes

\begin{tabular}{|c|c|c|c|}
\hline & $\begin{array}{l}\text { Mild/ } \\
\text { moderate }\end{array}$ & Severe & $p$ \\
\hline Female, $n(\%)$ & $122(66 \cdot 0)$ & $498(74 \cdot 8)$ & $0 \cdot 04$ \\
\hline Mean age, years (s.D.) & $50 \cdot 7(13 \cdot 9)$ & $44 \cdot 0(13 \cdot 6)$ & $<0.0001$ \\
\hline Mean screen score (S.D.) & $6 \cdot 2(1 \cdot 4)$ & $7 \cdot 5(1 \cdot 8)$ & $<0.001$ \\
\hline \multicolumn{4}{|l|}{ Marital status, $n(\%)$} \\
\hline Single & $17(9 \cdot 1)$ & $108(16 \cdot 2)$ & $0 \cdot 002$ \\
\hline Married & $135(72 \cdot 6)$ & $388(58 \cdot 4)$ & \\
\hline $\begin{array}{l}\text { Separated/divorced/ } \\
\text { widowed }\end{array}$ & $34(18 \cdot 3)$ & $169(25 \cdot 4)$ & \\
\hline \multicolumn{4}{|l|}{ Employment, $n(\%)$} \\
\hline Employed & $98(52 \cdot 7)$ & $333(50 \cdot 2)$ & $0 \cdot 15$ \\
\hline Unemployed & $4(2 \cdot 2)$ & $35(5 \cdot 3)$ & \\
\hline Inactive & $84(45 \cdot 2)$ & $296(44 \cdot 6)$ & \\
\hline $\begin{array}{l}\text { Rented accommodation, } \\
n(\%)\end{array}$ & $49(26 \cdot 3)$ & $220(33 \cdot 0)$ & $0 \cdot 06$ \\
\hline No car access, $n(\%)$ & $25(13 \cdot 4)$ & $122(18 \cdot 0)$ & $0 \cdot 15$ \\
\hline \multicolumn{4}{|l|}{ Education, $n(\%)$} \\
\hline A level + & $50(27 \cdot 5)$ & $187(28 \cdot 4)$ & $0 \cdot 30$ \\
\hline GCSE or equivalent & $75(41 \cdot 2)$ & $305(46 \cdot 3)$ & \\
\hline No qualifications & $57(31 \cdot 3)$ & $167(25 \cdot 3)$ & \\
\hline \multicolumn{4}{|l|}{ Financial strain, $n(\%)$} \\
\hline Comfortable/alright & $134(72 \cdot 8)$ & $423(63 \cdot 9)$ & $0 \cdot 04$ \\
\hline Difficult or very difficult & $50(27 \cdot 2)$ & $239(36 \cdot 1)$ & \\
\hline
\end{tabular}

S.D., Standard deviation.

a Totals do not always add up to 866 because of missing data.

after rotation, by the inclusion of more than three factors.

Factor loadings after rotation are shown in Table 2. Eight items had high positive loadings on the first factor, and reflected concerns about the emotional instability of people with depression, the shamefulness of the condition and the poor prognosis. We entitled this factor 'depression as permanent, disabling and stigmatizing'. Three items were highly and positively loaded on the second factor. These items encompass a more sympathetic and understanding attitude to depression, which is seen as a medical condition that can affect anyone. We have called this 'depression is a medical condition that responds to support'. Two items had high loadings (one of which had a negative sign) on the third factor. These items were concerned with antidepressants. The positive loaded item was 'antidepressants are addictive', while the negatively loaded item was 'antidepressants are an effective way of treating depression'. We have

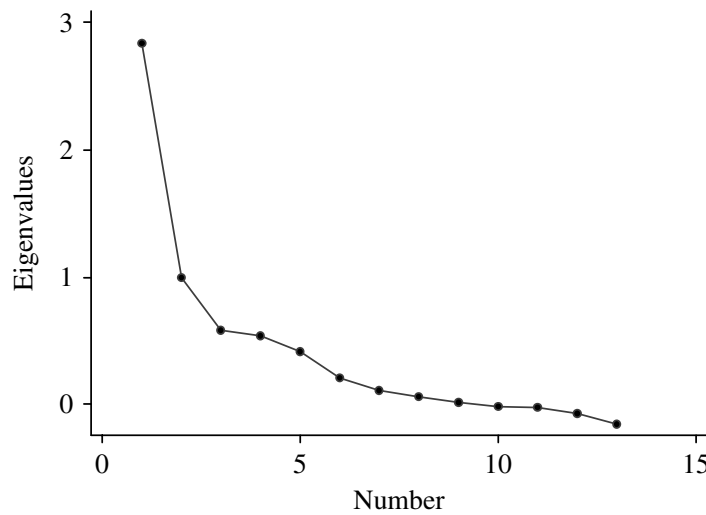

FIG. 1. Scree plot derived from principal factor analysis of the Attitudes to Depression and its Treatment (AdepT) questionnaire.

therefore called this factor 'antidepressants are addictive and ineffective'.

These results were largely unchanged when the sample was stratified by severity of depressive episode as in Table 1. The results for the severe depression group were almost identical to those in the sample as a whole. The results were slightly different in the mild and moderate depressive episode group. Although the same three-factor solution pertained, factor loadings were subtly different. On factor 1 , item 6 'If you have depression, you should be able pull to yourself together' (factor loading 0.41) replaced item 17 'When I have been depressed in the past, I have kept it a secret' $(0 \cdot 48)$. On factor 2 , loadings on items 9 'Depression is a medical condition, just like any other illness' and 18 'Anybody can suffer from depression' were reduced very slightly, to just below $0 \cdot 40$. Loadings on factor 3 were unchanged.

\section{Tests of study hypotheses}

Those who reported receiving and adhering to evidence-based antidepressant medication for the index episode had significantly lower scores on factor 1 (depression as permanent, disabling and stigmatizing) and factor 3 (antidepressants are addictive and ineffective) and higher scores on factor 2 (depression is a medical condition that responds to support) (Table 3). A similar pattern was seen for receipt and adherence to psychological treatments, although this did not reach statistical significance for factor 1 . Those who reported disclosure (telling family and/or 
Table 2. Results of principal factor analysis of responses to the AdepT questionnaire, showing item loadings on three retained factors after varimax rotation. Items concerning treatment are shown in bold

\begin{tabular}{|c|c|c|c|}
\hline Item & Factor 1 & Factor 2 & Factor 3 \\
\hline 1. Depression is a sign of weakness & $0 \cdot 61$ & $-0 \cdot 14$ & $0 \cdot 20$ \\
\hline 2. People with depression are more creative and imaginative than others & $0 \cdot 05$ & $-0 \cdot 01$ & $-0 \cdot 01$ \\
\hline 3. People with depression are hard to talk to & $0 \cdot 42$ & $-0 \cdot 05$ & $0 \cdot 09$ \\
\hline 4. People who have experienced depression are understanding and compassionate & $0 \cdot 03$ & $0 \cdot 30$ & $-0 \cdot 05$ \\
\hline 5. People with depression deserve a lot of support from their friends and family & $-0 \cdot 01$ & $\mathbf{0} \cdot 50$ & $-0 \cdot 05$ \\
\hline 6. If you have depression, you should be able pull to yourself together & $0 \cdot 36$ & $-0 \cdot 26$ & $0 \cdot 31$ \\
\hline 7. Counselling is an effective way of treating depression & $0 \cdot 002$ & $0 \cdot 34$ & $-0 \cdot 20$ \\
\hline 8. Depressed people are often unstable & $0 \cdot 53$ & $0 \cdot 02$ & $-0 \cdot 05$ \\
\hline 9. Depression is a medical condition, just like any other illness & $-0 \cdot 13$ & $0 \cdot 46$ & $-0 \cdot 18$ \\
\hline 10. People with depression are a danger to others & $0 \cdot 46$ & $-0 \cdot 13$ & $-0 \cdot 001$ \\
\hline 11. Depression does not usually get better with treatment & $0 \cdot 25$ & $-0 \cdot 20$ & $0 \cdot 36$ \\
\hline $\begin{array}{l}\text { 12. You must be careful not to upset someone who has been } \\
\text { depressed, or they will get ill again }\end{array}$ & $0 \cdot 42$ & $-0 \cdot 06$ & $0 \cdot 15$ \\
\hline 13. Antidepressants are an effective way of treating depression & $-0 \cdot 03$ & $0 \cdot 16$ & $-0 \cdot 54$ \\
\hline 14. People who have suffered from depression never recover & $0 \cdot 43$ & $-0 \cdot 20$ & $0 \cdot 17$ \\
\hline 15. Depression is always caused by problems in people's lives & $0 \cdot 26$ & $0 \cdot 12$ & $0 \cdot 27$ \\
\hline 16. If other people knew I had been depressed, they would think less of me & $0 \cdot 50$ & $0 \cdot 09$ & $0 \cdot 10$ \\
\hline 17. When I have been depressed in the past, I have kept it a secret & $0 \cdot 42$ & $0 \cdot 07$ & $0 \cdot 19$ \\
\hline 18. Anybody can suffer from depression & $-0 \cdot 15$ & $0 \cdot 43$ & $-0 \cdot 02$ \\
\hline 19. Antidepressants are addictive & $0 \cdot 18$ & -0.002 & $0 \cdot 58$ \\
\hline
\end{tabular}

AdepT, Attitudes to depression and its treatment.

Table 3. Unadjusted mean difference in ADepT factor scores between those who received and adhered to evidence-based treatments and those who did not, and between those who disclosed their depressive episode to family and/or friends and those who did not

\begin{tabular}{|c|c|c|c|c|c|c|}
\hline Factor & $\begin{array}{c}\text { Medication, mean } \\
\text { difference (S.E.) }\end{array}$ & $p$ & $\begin{array}{l}\text { Psychological treatment, } \\
\text { mean difference (s.E.) }\end{array}$ & $p$ & $\begin{array}{c}\text { Disclosure, mean } \\
\text { difference (S.E.) }\end{array}$ & $p$ \\
\hline 1 Permanent, disabling and stigmatizing & $-0 \cdot 13(0 \cdot 06)$ & $0 \cdot 02$ & $0 \cdot 08(0 \cdot 10)$ & $0 \cdot 39$ & $-0 \cdot 24(0 \cdot 07)$ & $0 \cdot 001$ \\
\hline 2 Medical condition that responds to support & $0 \cdot 16(0 \cdot 04)$ & $0 \cdot 001$ & $0.22(0.08)$ & $0 \cdot 01$ & $0.29(0.06)$ & $<0 \cdot 001$ \\
\hline 3 Antidepressants are addictive and ineffective & $-0.51(0 \cdot 04)$ & $<0 \cdot 001$ & $-0.27(0.09)$ & $0 \cdot 003$ & $-0 \cdot 12(0 \cdot 05)$ & $0 \cdot 03$ \\
\hline
\end{tabular}

AdepT, Attitudes to depression and its treatment; s.E., standard error.

friends about their depressive episode) had significantly higher scores on factor 2 and lower scores on factors 1 and 3 .

\section{DISCUSSION}

One of the most notable findings from this research was the subtle range of attitudes about depression and its outcome that we elicited. This view was supported by the modest internal reliability of the 19-item ADepT questionnaire, and by the results of factor analysis. We identified three factors within the responses to this instrument. The first factor had high loadings from items reflecting a view of depression as a permanent, disabling and stigmatizing mental breakdown from which there was little prospect of recovery. The second factor reflected a more sympathetic view of depression as a medical condition that could affect anyone and from which recovery was possible with support and help. Finally, a third, bipolar, factor concerned antidepressant medication, with high scores indicating a view of these as ineffective and addictive. Further analysis revealed little variation with depression severity, although among those with mild and moderate depression there was some evidence of less concern with concealment and a more normalizing attitude to recovery.

Despite the relative clarity of interpretation, we cannot be certain of the direction of these associations; such attitudes may determine 
concordance with treatments, or experiences of treatment and support may lead to these attitudes to depression. These findings do, however, stand in contrast to many previous reports, which have tended to concentrate almost exclusively on dichotomous views about the acceptability or otherwise of treatment (Pyne et al. 2005).

\section{Strengths and weaknesses of the study}

The present findings are based on a very large sample of individuals with ICD-10 depressive episodes in the 12 months preceding interview, the majority of which were of at least moderate severity. These individuals were recruited from among consecutive primary care attendees, and depressive episodes were confirmed using a validated, standardized clinical interview. The 36 participating practices were recruited from across England and Wales. This is one of the largest, most diverse and best validated samples of this type ever recruited in the UK. By recruiting individuals with a depressive episode at any time in the preceding 12 months, our sample was likely to be more representative of all those with depression than cross-sectional samples of those with current depression, in terms of attitudes to this condition and its treatment (Singleton et al. 2001). Cross-sectional samples are likely to include substantial numbers of those with chronic depression as well as those with episodes of recent onset. Thus, a prevalence sample will include many who are treatment resistant (or treatment reluctant), as well as those who have not yet had the opportunity to experience treatment.

One weakness of this study was the high rate of attrition between screening and interview. Although non-participation may limit the generalizability of study findings, it does not usually affect their validity (Hennekens \& Buring, 1987). Although less than half of those who were eligible for the second-stage interview agreed to take part, screening questionnaire scores did not differ significantly between those who were and were not interviewed. Nevertheless, we cannot exclude the possibility that those who were interviewed differed in other ways, including their willingness to receive and adhere to treatment. Although scores on the ADepT questionnaire might not be wholly representative of those with a history of moderate or severe depression, it is unlikely that nonparticipation at interview would have resulted in biased estimates of association between attitudinal measures and either treatment receipt/ adherence or disclosure. For this to have occurred, non-participation would have to have been associated with both attitudes to depression and treatment receipt or disclosure.

A further weakness is that the ADepT questionnaire is in effect a new instrument; although based on items from other measures, we cannot be wholly certain of their reliability. We would, however, argue that the criterion validity of this questionnaire was evidenced by the patterns of association between factor scores and indices of treatment receipt/adherence, and disclosure.

Identifying and quantifying the adequacy of treatment delivery and adherence is extremely challenging, and despite the proliferation of different ways of measuring adherence, there is no agreed gold standard (Garber et al. 2004; DiMatteo \& Haskard, 2006). We chose to rely on patient reports in both instances in the context of a comprehensive, structured face-to-face interview. We were careful to begin by eliciting evidence of a depressive episode in the preceding 12 months, and then using this to anchor the remainder of the interview, which covered the onset and duration of symptoms, and related help-seeking. We enumerated all possible pharmacological and psychological treatments, and asked about the dose, duration and circumstances of termination for each. Although this method was not formally validated, the approach was thorough and systematic. By recording both the names and doses of different medications, it is unlikely that rates of prescribing were over-reported. We would also argue that the pattern of associations with responses to the ADepT questionnaire provides evidence of the validity of our treatment receipt and adherence data. While some psychiatrists might view the treatment criteria as potentially inclusive of subtherapeutic interventions, these were entirely in keeping with previous research in community and primary care settings (Wang et al. 2005). For this reason, we described these collectively as 'minimally adequate treatment'. The most important point is that these criteria were operationalized and applied systematically and without bias to the entire sample. 


\section{Future directions}

These findings highlight the need for GPs to explore people's attitudes to depression prior to considering treatments, and indeed it might be argued that this should be part of the assessment of depression. However, it is important to stress that this study cannot distinguish between attitudes as the cause or consequence of specific treatment experiences. While it might be that particular views (such as seeing depression as a medical condition likely to respond to treatment) could enhance treatment receipt and adherence, it is also possible that the attitudes elicited were shaped by treatment experiences. There is now a need for longitudinal research to explore this further, as well as intervention studies to evaluate the mediating or modifying effects of patients' beliefs and attitudes on treatment outcomes.

\section{CONCLUSIONS}

Even after experiencing a moderate or severe depressive episode, individuals continue to have very subtle and often divergent views about this condition, its outcome, and the most appropriate forms of help. These go far beyond whether particular treatments are acceptable or not, and encompass beliefs about the nature and causes of depression itself. Such beliefs are likely to have significant implications for help seeking, consultation outcomes and adherence to treatment.

\section{ACKNOWLEDGEMENTS}

This study was funded by the Medical Research Council under the Health of the Public Initiative, grant number G9900548. We thank our colleagues at the GPRF for their contribution, particularly Louise Letley, and the many research nurses who collected the data.

\section{DECLARATION OF INTEREST}

None.

\section{REFERENCES}

Anderson, C. M., Robins, C. S., Greeno, C. G., Cahalane, H., Copeland, V. C. \& Andrews, R. M. (2006). Why lower income mothers do not engage with the formal mental health care system: perceived barriers to care. Qualitative Health Research 16, 926-943.

Bebbington, P. E., Brugha, T. S., Meltzer, H., Jenkins, R., Ceresa, C., Farrell, M. \& Lewis, G. (2000). Neurotic disorders and the receipt of psychiatric treatment. Psychological Medicine 30, 1369-1376.

Botega, N., Mann, A., Blizard, R. \& Wilkinson, G. (1992). General practitioners and depression - first use of the Depression Attitude Questionnaire. International Journal of Methods in Psychiatric Research 2, 169-180.

Brugha, T. S. (1995). Depression undertreatment: lost cohorts, lost opportunities? Psychological Medicine 25, 3-6.

Brugha, T. S., Bebbington, P. E., Singleton, N., Melzer, D., Jenkins, R., Lewis, G., Farrell, M., Bhugra, D., Lee, A. \& Meltzer, H. (2004). Trends in service use and treatment for mental disorders in adults throughout Great Britain. British Journal of Psychiatry $\mathbf{1 8 5}$, 378-384.

Cattell, R. B. (1966). The scree test for the number of factors. Multivariate Behavioral Research 1, 245-276.

Cooper-Patrick, L., Powe, N. R., Jenckes, M. W., Gonzales, J. J., Levine, D. M. \& Ford, D. E. (1997). Identification of patient attitudes and preferences regarding treatment of depression. Journal of General Internal Medicine 12, 431-438.

Demyttenaere, K., Bruffaerts, R., Posada-Villa, J., Gasquet, I., Kovess, V., Lepine, J. P., Angermeyer, M. C., Bernert, S., de Girolamo, G., Morosini, P., Polidori, G., Kikkawa, T., Kawakami, N., Ono, Y., Takeshima, T., Uda, H., Karam, E. G., Fayyad, J. A., Karam, A. N., Mneimneh, Z. N., Medina-Mora, M. E., Borges, G., Lara, C., de Graaf, R., Ormel, J., Gureje, O., Shen, Y., Huang, Y., Zhang, M., Alonso, J., Haro, J. M., Vilagut, G., Bromet, E. J., Gluzman, S., Webb, C., Kessler, R. C., Merikangas, K. R., Anthony, J. C., Von Korff, M. R., Wang, P.S., Brugha, T. S., Aguilar-Gaxiola, S., Lee, S., Heeringa, S., Pennell, B. E., Zaslavsky, A. M., Ustun, T. B. \& Chatterji, S. (2004). Prevalence, severity and unmet need for treatment of mental disorders in the World Health Organization World Mental Health Surveys. Journal of the American Medical Association 291, 2581-2590.

Department of Health (2001). Treatment Choice in Psychological Therapies and Counselling: Evidence Based Clinical Practice Guideline. Department of Health: London.

DiMatteo, M. R. \& Haskard, K. B. (2006). Further challenges in adherence research. Medical Care 44, 297-299.

Dwight-Johnson, M., Sherbourne, C. D., Liao, D. \& Wells, K. B. (2000). Treatment preferences among depressed primary care patients. Journal of General Internal Medicine 15, 527-534.

Edlund, M. J., Wang, P. S., Berglund, P. A., Katz, S. J., Lin, E. \& Kessler, R. C. (2002). Dropping out of mental health treatment: patterns and predictors among epidemiological survey respondents in the United States and Ontario. American Journal of Psychiatry 159, 845-851.

Garber, M., Nau, D., Erickson, S., Aikens, J. \& Lawrence, J. (2004). The concordance of self-report with other measures of medication adherence: a summary of the literature. Medical Care 42, 649-652.

Hennekens, C. H. \& Buring, J. E. (1987). Epidemiology in Medicine. Little, Brown: Boston.

Jorm, A. F., Griffiths, K. M., Christensen, H., Parslow, R. A. \& Rogers, B. (2004). Actions taken to cope with depression at different levels of severity: a community survey. Psychological Medicine 34, 293-299.

Kendrick, T. (2000). Why can't GPs follow guidelines on depression? British Medical Journal 320, 200-201.

Kessing, L., Hansen, H. V., Demyttenaere, K. \& Bech, P. (2005). Depressive and bipolar disorders: patients' attitudes and beliefs towards depression and antidepressants. Psychological Medicine 35, 1205-1213.

King, M., Nazareth, I., Lampe, F., Bower, P., Chandler, M., Morou, M., Sibbald, B. \& Lai, R. (2005). Impact of participant and physician intervention preferences on randomized trials: a systematic review. Journal of the American Medical Association 293, 1089-1099.

Layard, R. (2006). The case for psychological treatment centres. British Medical Journal 332, 1030-1032. 
Lin, E. \& Parikh, S. V. (1999). Sociodemographic, clinical, and attitudinal characteristics of the untreated depressed in Ontario. Journal of Affective Disorders 53, 153-162.

Lin, P., Campbell, D. G., Chaney, E. F., Liu, C.-F., Heagerty, P., Felker, B. L. \& Hedrick, S. C. (2005). The influence of patient preference on depression treatment in primary care. Annals of Behavioral Medicine 30, 164-173.

Murray, C. J. L. \& Lopez, A. D. (1997). Alternative projections of mortality and disability by cause 1990-2020: Global Burden of Disease Study. Lancet 349, 1498-1504.

NICE (2004). Management of Depression in Primary and Secondary Care. Clinical Guideline 23. National Institute for Clinical Excellence: London.

Nutting, P., Rost, K., Dickinson, M., Werner, J. J., Dickinson, P., Smith, J. L. \& Gallovic, B. (2002). Barriers to initiating depression treatment in primary care practice. Journal of General Internal Medicine 17, 103-111.

Priest, R. G., Vize, C., Roberts, A., Roberts, M. \& Tylee, A. (1996). Lay people's attitudes to treatment of depression: results of opinion poll for Defeat Depression Campaign just before its launch. British Medical Journal 313, 858-859.

Pyne, J. M., Rost, K. M., Farahati, F., Tripathi, S. P., Smith, J., Williams, K. D., Fortney, J. \& Coyne, J. C. (2005). One size fits some: the impact of patient treatment attitudes on the costeffectiveness of a depression primary care intervention. Psychological Medicine 35, 839-854.

Rost, K., Nutting, P., Smith, J., Werner, J. \& Duan, N. (2001) Improving depression outcomes in community primary care practice: a randomized trial of the quEST intervention. Quality Enhancement by Strategic Teaming. Journal of General Internal Medicine 16, 143-149.
Scott, J. (2006). Depression should be managed like a chronic disease. British Medical Journal 332, 985-986.

Singleton, N., Bumpstead, R., O'Brien, M., Lee, A. \& Meltzer, H. (2001). Psychiatric Morbidity Among Adults Living in Private Households, 2000. The Stationery Office: London.

StataCorp (2004). Stata Statistical Software: Release 8.0. Stata Corporation: College Station, TX

Thomas, C. M. \& Morris, S. (2003). Cost of depression among adults in England in 2000. British Journal of Psychiatry $\mathbf{1 8 3}$ 514-519.

Thompson, C., Kinmonth, A.-L., Stevens, L., Peveler, R. C., Stevens, A., Ostler, K. J., Pickering, R. M., Baker, N. G., Henson, A. Preece, J., Cooper, D. \& Campbell, M. J. (2000). Effects of clinicalpractice guideline and practice-based education on detection and outcome of depression in primary care: Hampshire Depression Project randomised controlled trial. Lancet 355, 185-191.

Wang, P. S., Lane, M., Olfson, M., Pincus, H. A., Wells, K. B. \& Kessler, R. C. (2005). Twelve-month use of mental health services in the United States. Archives of General Psychiatry 62, 629-640.

Weich, S. \& Lewis, G. (1998). Poverty, unemployment and common mental disorders: population-based cohort study. British Medical Journal 317, 115-119.

WHO (1993). The ICD-10 Classification of Mental and Behavioural Disorders: Diagnostic Criteria for Research. World Health Organization: Geneva.

WHO (1997). Composite International Diagnostic Interview (Core Version 2.1). World Health Organization: Geneva.

Young, A. S., Klap, R., Sherbourne, C. D. \& Wells, K. B. (2001) The quality of care for depressive and anxiety disorders in the United States. Archives of General Psychiatry 58, 55-61. 